May 2012

\title{
Closing the Research/Practice Gap: The Journey from Student to Practitioner
}

Stacey Nordlund

San Jose State University, staceynordlund@gmail.com

Follow this and additional works at: https://scholarworks.sjsu.edu/ischoolsrj

Part of the Library and Information Science Commons

\section{Recommended Citation}

Nordlund, S. (2012). Closing the Research/Practice Gap: The Journey from Student to Practitioner. School of Information Student Research Journal, 2(1). https://doi.org/10.31979/2575-2499.020101 Retrieved from https://scholarworks.sjsu.edu/ischoolsrj/vol2/iss1/1

This article is brought to you by the open access Journals at SJSU ScholarWorks. It has been accepted for inclusion in School of Information Student Research Journal by an authorized administrator of SJSU ScholarWorks. For more information, please contact scholarworks@sjsu.edu. 
Closing the Research/Practice Gap: The Journey from Student to Practitioner

Keywords

editorial, literature review, scholarship, research writing 
Closing the Research/Practice Gap: The Journey from Student to Practitioner

The field of library and information science (LIS) is vast and its practitioners are present in libraries, archives, museums, and in corporate and other information organizations. Regardless of the type of working environment, librarians must be prepared to undertake some form of research activities through their work in order to participate fully as members of the LIS community. The act of participating in or leading a research project is invoked whether one's practice exists in the form of a member of an academic research community, as a solo librarian running an information center in a corporate organization, or as a service-oriented children's librarian developing new programs and services. Throughout my career-which, thus far, has included experience in public, academic, and special libraries-the importance of research as a unifying element among disparate environments has been quite clear. Although each organization articulates unique missions, goals, and objectives, each of these information environments uses knowledge developed through research to support these missions, goals, and objectives. The broad array of research possibilities for LIS practitioners is also clearly evident in the wide variety of topics and research paradigms that are featured in not only this particular issue of the Student Research Journal (SRJ), but our publication as a whole.

It is important to point out, however, that a significant gap between research and practice has been frequently noted in the LIS literature. Haddow \& Klobas (2004) note the flaws in communication of research to practice, specifically in the LIS field. In a review of the existing literature, Haddow \& Klobas determined that practitioners lacked motivation or interest in conducting research, tended to avoid participation in research work, lacked knowledge and skill in conducting research, and spent most of their time focusing on day-to-day operations rather than conducting reading or research activities. This disconnect between research and practice may potentially be rectified by increasing practitioner involvement in the research process (Haddow \& Klobas, 2004). Increasing involvement in the research process can be initiated in the early stages of a career in the LIS field. Beginning at the student level, a research methods class, such as the one required in San José State University's (SJSU) School of Library and Information Science (SLIS) Master of Library and Information Science (MLIS) program, serves as an excellent foundation that opens the door to increased understanding of and participation in research activities throughout one's professional career.

It is key to build this foundation in soon-to-be LIS professionals as they initiate their graduate education. In this issue of $S R J$, our authors demonstrate not only the merit of developing a comprehensive understanding of research methods in order to approach a research question or problem, but, more specifically, the 
importance of clearly articulating a research question in order to pursue a problem in an organized way. It is fruitless to undertake new projects, propose systemic changes, or develop innovative programs and services without developing a plan based on an examination of the existing research or by undertaking a primary research project based on a specific research question. In order to successfully participate in the research process, it is essential to develop at least a foundational understanding of the research paradigms underpinning the chosen field.

Even those who claim to be "not interested" in research, or who fail to see its value, may experience a change of heart once they have broadened their understanding of the concepts and applications through a LIS research methods class. In this issue's Invited Contribution, Dr. Lili Luo, Assistant Professor at SJSU SLIS, uses the results of her research study to demonstrate the importance of formal research methods classes in LIS programs to enhance practitioner work in the LIS field. Dr. Luo (2012) conducted a survey study "to examine how taking research methods courses affects LIS practice, hoping to generate more awareness about the value of research methods education among LIS practitioners, encourage them to apply research to enhance practice, and promote the evidencebased culture in LIS" (p. 2). The responses she received were favorable towards making research methods courses a mandatory component of LIS programs. Dr. Luo (2012) concludes,

LIS students, when preparing themselves for professional careers, need to have a grounded understanding of how research can help them with their professional practice, equip themselves with the necessary knowledge and skills from the research methods course, and better yet, have a genuine interest in research and discovery. (p. 6)

In developing this knowledge and understanding of research methods, students prepare themselves adequately for their future careers and for continued participation in some form, even after completing their academic work and moving into practice. This participation may take, on one hand, the form of directly conducting research in the field, in a variety of environments. On the other hand, this continued participation may take the form of reading and interpreting research; participating in the discourse informally, or sharing knowledge through a variety of means.

In "Certification of Librarians: An Unproven Demand," Jonathan Pacheco Bell considers the purpose of professional certification and its relation to LIS professionals in the United States. He asks,

In light of the increasing complexity and evolving role of librarianship in the 21 st century, proper librarian training and qualifications are paramount 
concerns to practitioners and the public alike. Accordingly, this paper examines the following research question: Is certification of librarians necessary to ensure high quality service? (Bell, 2012, p. 2)

This question is addressed throughout the paper as Bell defines certification, provides an historical survey of LIS certification initiatives, and analyzes the arguments both in favor of and against librarian certification in an in-depth review of the literature. In the end, Bell (2012) concludes by answering the question; he asserts that certification cannot be deemed necessary to ensure high quality library service. Rather, he argues, the complexity of the evolving role of the librarian in combination with the expansive bureaucracy that would be necessarily put into place to support a certification program render "the case for certification...unconvincing" (p. 20). This is research that shapes practice, by introducing a clear, concise question of relevance to current practice, and by considering this question in an in-depth exploration of the literature.

Jonathan Pacheco Bell is an MLIS student at SJSU-SLIS and a Research Assistant for SJSU's IMLS grant-funded national study "Making Space for Young Adults in Public Libraries: Establishing a Research Foundation." Jonathan received his M.A. in Urban Planning from UCLA and studied political science and architecture as an undergraduate. He works as an urban planner in Los Angeles, CA.

In "An Exploratory Study of Online Information Regarding Colony Collapse Disorder," Meredith K. Boehm reviews information dissemination and web-based communication practices in the context of Colony Collapse Disorder (CCD), a current phenomenon resulting in declining honey bee populations. Boehm's study uses content analysis to compare information presented on four U.S. government websites and asks whether these information sources present CCD comprehensively to a broad spectrum of readers. She also considers which information topics are well-presented and which are missing or incomplete from these web-based information sources. The results from the content analysis show a combination of both strengths and weaknesses in existing government information sources. Boehm (2012) notes three specific findings needing further exploration: "the lack of current information, the need for network landscape mapping to understand the nuances of the connections between the entities, and the lack of interactivity and public engagement" (p. 14).

Boehm's study clearly demonstrates the relationship between research and application, and the importance of clearly stating a specific research problem when undertaking an exploratory research project. Specific questions are asked and answered, and future research may expand on these questions by using the 
same framework in the study of additional content areas and/or additional information sources for CCD information. In this way, the research process develops gradually from one source to the next, continually evolving and producing new insights and discoveries. All may be achieved within the context of practice.

Meredith K. Boehm is a Knoxville, Tennessee native with a bachelor's degree in ceramic arts from the Maryland Institute College of Art in Baltimore, Maryland. Currently preparing to begin doctoral studies in information sciences and communication, Meredith's research interests focus on the intersection of egovernment and e-science, citizen involvement in complex scientific problem solving, and the systemic function of large-scale data infrastructures for environmental science research. Meredith has been fortunate to work as a graduate teaching and research assistant for Dr. Vandana Singh and Dr. Dania Bilal as a master's degree student at the University of Tennessee School of Information Sciences. Meredith also performed a role as a paid intern at the Oak Ridge National Laboratory's Distributed Active Archive Center for Biogeochemical Dynamics (DAAC) and contributed to NASA's FLUXNET network database and other climate change data archiving projects at the DAAC. In the future Meredith's goal is to achieve a position as a research professional, publishing scholarly work as a representative of an academic institution and to teach students as a professor of information sciences specializing in science communication studies.

Kathy J. Fatkin explores the evolution of U.S. hospitals and medical libraries, and the changing role of the librarian in "Using Organization Theory to Explore the Changing Role of Medical Libraries." Fatkin (2012) asks, "Can organization theory explain the changes in United States (U.S.) medical libraries and the services professional librarians provide to the hospital staff?" This historical research review begins with an overview of organization theory, and describes the development of U.S. hospitals and medical libraries over the last century. Fatkin then discusses the rise in evidence-based practice in healthcare, which mirrors the current state of LIS research. She notes,

Evidence-based healthcare is a valuable tool in reducing the gap between what we know from research and what we do in practice.... The medical librarian, who is comfortable with reading research and translating findings for others, can easily fulfill the role of informationist or knowledge broker. Outside forces are once again reshaping the responsibilities of the medical librarian. (Fatkin, 2012, p. 10) 
The necessity of developing a comprehensive understanding of the research process, therefore, is not merely to act successfully as participant in the act of conducting primary research, but, equally importantly, as translator of existing work. Librarians do not simply provide generic information to users; rather we define, instruct, and delve into explanation of complex materials-including research findings. As LIS research develops further as an evidence-based practice, the research/practice gap may be minimized if practitioners continue to develop skills in this area.

Kathy J. Fatkin is a doctoral student at Emporia State University in Emporia, Kansas. She works at Eastern Idaho Regional Medical Center as a solo librarian in the medical library and she is also a registered nurse. Her research interests include how nurses use information to improve patient care and how the health science librarian can better serve nurses in acute care settings.

Camelia Naranch assesses how law librarians support the efforts of legal scholars in the study of foreign, comparative, and international law in "International Legal Collections at U.S. Academic Law School Libraries." Naranch opens her article with a description of the current state of foreign, comparative, and international law training in law schools, and then moves into a description of the collections and resources that are available to support these students in their training. Naranch (2012) surveys legal collections-print, online research guides, and databases - at twelve public and private U.S. academic libraries, and queries "how law librarians are participating in the process of creating new fields of international legal research and training" (p. 2).

Naranch (2012) notes the role law librarians play in ensuring global access to information, ensuring accuracy and currency of information, and preserving knowledge for future generations of use. She concludes that "as committed information professionals, they have been actively involved in all stages of the process" (p. 13), including as teachers, as information specialists, as advocates for open access, and as critical observers of legal collection development and management. Again, we see the relationship between research and practice as librarians translate research into information that is both usable for and understood by law students. This is achieved through individual or group research consultation as well as through the creation of new reference materials and research guides, both print and online.

Camelia Naranch is a serials specialist at the Robert Crown Law Library at Stanford University and an MLIS student at San Jose State University. She may be contacted at cnaranch@law.stanford.edu. 
The LIS research community is growing, and it is vital for LIS professionals to maintain an understanding of research paradigms and to remain active in current scholarly discourse. Only in this way are we able to make worthwhile contributions to the field, whether as researcher or as practitioner. By developing knowledge of the current state of research, we can adapt our practices accordingly. In this way, we may resolve the disconnect experienced by practitioners as presented by Haddow and Klobas (2004). This journey begins through the mandatory completion of a graduate research methods class, and is continued through participation in scholarly activities and consumption of LIS literature throughout one's career. The Student Research Journal serves as a source for student education and enhanced research skills development through three modes of participation: as editor, as author, or as reader. Whether as editor, author, or reader, students are trained in research methods as well as in the importance of structuring a research paper by forming a clearly articulated research question. In the journey from student to practitioner this experiencebased knowledge will be retained and we will more easily bridge the gap between research and practice.

\section{References}

Haddow, G., \& Klobas, J. E. (2004). Communication of research to practice in library and information science: Closing the gap. Library \& Information Science Research, 26(1), 26-43. 